\title{
COMUNICAÇÃO ALTERNATIVA E AMPLIADA (CAA) NA PERSPECTIVA DA EDUCAÇÃO INCLUSIVA DE DEFICIENTES INTELECTUAIS: UMA ABORDAGEM DA TEORIA HISTÓRICO CULTURAL (THC)
}

\section{COMMUNICATION ALTERNATIVE AND EXTENDED (CAA) EDUCATION IN PERSPECTIVE INCLUSIVE OF INTELLECTUAL DISABILITIES: AN APPROACH OF CULTURAL HISTORY THEORY (THC )}

Maria do Socorro Castelo Branco Mourão Lima ${ }^{1}$

\section{RESUMO}

Este artigo propõe analisar a CAA (Comunicação Alternativa e Ampliada) na perspectiva da Educação Inclusiva numa abordagem da Teoria Histórico Cultural (THC). O artigo destaca a Comunicação Alternativa e Ampliada, utilizada como meio de inclusão escolar e social de deficientes, principalmente, deficientes intelectuais. Utiliza-se, neste artigo, o aporte teórico de Vygotsky (1984). A THC, defendida pelo estudioso russo e seus colaboradores, baseiase na lei geral do desenvolvimento cultural, em dois níveis: primeiramente, interpessoal e depois intrapessoal. No entanto, o autor assegura que somente através das relações sociais carregadas de significações, surge 0 desenvolvimento das funções psicológicas superiores ou culturais mediadas pelo outro, por meio da linguagem, signo por excelência. Isto é, a essência do desenvolvimento cultural consiste na apropriação e no domínio do social. Este artigo enfatiza o conceito da zona de desenvolvimento proximal (ZDP) como foco do estudo da CAA. A pesquisa é somente bibliográfica e o referencial teórico contempla três tópicos: 1- A Comunicação Alternativa e Ampliada para deficientes Intelectuais; 2- Inclusão escolar / necessidades educacionais especiais / deficiente intelectual 3- O sociointeracionismo da Teoria Histórico Cultural de Vygotsky e a CAA (Comunicação Alternativa e Ampliada).

Palavras-chave: Comunicação Alternativa e Ampliada (CAA) - Inclusão Escolar - Teoria Histórico Cultural (THC).

\section{ABSTRACT}

This article aims to analyze the AAC (Augmentative and Alternative Communication) from the perspective of an approach Inclusive HistoricalCultural Theory (HCT). The article highlights the Alternative Communication and Extended, used as a means of educational and social inclusion of disabled mainly intellectual disabilities. It is used in this article, the theoretical framework of Vygotsky (1984). The THC, supported by the Russian scholar and his colleagues, is based on the general law of cultural development, on two levels: first, interpersonal and intrapersonal later. However, the author ensures that only through the loaded social relationships of meanings, the development of superior arises cultural or psychological functions mediated by other by means of language, sign par excellence. This is the essence of cultural development is the ownership and in the field of social. This article emphasizes the concept of Zone of Proximal Development (ZPD) as the focus of the AAC study. Research is only literature and the theoretical framework covers three topics: 1- The 
Alternative Communication and Extended Disabled Intellectuals; 2- School inclusion / special needs / handicapped intellectual 3- The social interactionism Theory of Cultural History of Vygotsky and the CAA (Alternative Communication and Extended).

Keywords: Augmentative and Alternative Communication (AAC ) - School Inclusion - Historical-Cultural Theory (HCT ).

\section{INTRODUÇÃO}

Quando, entre indivíduos, ocorre a redução de comunicação oral face a face devido ao repertório verbal ser limitado, ininteligível ou mesmo quando não se manifesta, (apesar da linguagem oral não ser a única forma de comunicação), esta redução na comunicação afetará outras áreas do indivíduo como as relações sociais (interpessoais e intrapessoais), contudo interferindo no processo de aprendizagem.

Para esta população, são necessários dispositivos como sistemas de Comunicação Alternativa e Ampliada (CAA), oportunizando uma comunicação mais funcional e mais significativa no contexto socioafetivo.

A CAA tem sido comumente caracterizada como uma área da prática clínica que propõe compensar desordens na comunicação expressiva (temporárias ou não) devido aos prejuízos na linguagem (oral e escrita). Diferentes meios de comunicação derivados do uso de gestos, linguagem de sinais e expressões faciais figuras, símbolos, além de sofisticados sistemas computadorizados podem ser utilizados de forma complementar ou alternativa à linguagem oral, quando possível.

No Brasil, o emprego da CAA foi iniciado em instituições de reabilitação para portadores de deficiência física, especialmente paralisia cerebral. Nos últimos anos, houve um interesse crescente pela área também, com o intuito de oportunizar a inclusão de crianças em ambiente escolar com dificuldades na linguagem oral.

Vygotsky (2003), por meio do estudo da Teoria Histórico Cultural baseada no sociointeracionismo, mais precisamente com o conceito de ZDP (Zona de Desenvolvimento Proximal), contribuiu sobremaneira com os 
processos de aprendizagem em geral e, desta forma, com os estudos que subsidiam a relação entre indivíduo que necessita de CAA e seu mediador.

Essa teoria é importante para o estudo do Deficiente Intelectual que apresenta dificuldade com a linguagem oral. Portanto, também dificuldade de aprendizagem. A utilização dos recursos de CAA proporciona situações interativas, afetivas e facilitadoras de aprendizagem.

\section{COMUNICAÇÃO ALTERNATIVA E AMPLIADA PARA DEFICIENTES INTELECTUAIS}

A comunicação é imprescindível para a vida humana e, apesar de existirem outras formas de comunicação (gestos, expressões faciais, posturas e movimentos corporais e diagramas), a linguagem oral é a mais utilizada e geradora de desempenhos complexos. Durante o processo natural de desenvolvimento infantil, a criança passa a compartilhar do meio de comunicação utilizado pela família e grupo social a que pertence, aprendendo a conceituar os símbolos comunicativos (BLOOM; LAHEY, 1978). A linguagem oral é decisiva não só para a aquisição dos demais sistemas simbólicos (leitura, escrita, matemática), mas também para o desenvolvimento das relações interpessoais que, sem a fala, tornam-se comprometidas.

Portanto, estas pessoas tornam-se impossibilitadas de fazerem uso desta linguagem, por diversos motivos: neurológicos, físicos, emocionais e cognitivos (NUNES, 2003). Uma maneira de auxiliar estas pessoas no processo de comunicação é a Comunicação Alternativa e Ampliada (CAA), a Comunicação Alternativa e Suplementar (CAS), a Comunicação Suplementar e Alternativa (CSA) ou somente a Comunicação Alternativa (CA). Todas estas nomenclaturas são utilizadas na literatura brasileira de acordo com a tradução em que foram realizadas (REILY, 2009). A Comunicação Ampliada (argumentative communication) tem propósito duplo: promover ou suplementar a fala, contribuindo com outra maneira alternativa de comunicação se 0 indivíduo não se mostrar capaz de desenvolver a forma oral (VON TETZCHNER, 1997). Na definição de Nunes (2009, p.1), a Comunicação Alternativa é compreendida como "conjunto de métodos e técnicas que 
viabilizam a comunicação, complementando ou substituindo a linguagem oral comprometida ou ausente".

No caso específico da deficiência intelectual, não foge à regra, a criança também necessita da interação com seu meio social para aprender com seus pares a conceituar símbolos (VON TETZCHNER, 2009). Porém, nesta deficiência, os prejuízos no comportamento adaptativo, que inclui as habilidades de comunicação, levam a criança ao desenvolvimento deficitário da linguagem, sendo necessário lançar mão de recursos alternativos de comunicação para promover situações interativas (LUCKASSON et al., 2002). Quando o indivíduo é totalmente incapaz de se comunicar oralmente ou sua fala não é capaz de promover essa comunicação, é necessário que se faça uso de recursos alternativos a fim de restaurar o processo de interação desse sujeito com o mundo que o cerca (NUNES, 2008).

Classificam-se os tipos de recursos de comunicação alternativa (de acordo com o uso de tecnologia ou não) em três: o que não faz uso de nenhum material, a não ser o próprio corpo do interlocutor (sem tecnologia). Quando se utiliza pranchas comunicativas, álbuns, figuras (baixa tecnologia) e quando se fazem uso de vozes digitalizadas, pranchas eletrônicas, softwares (alta tecnologia).

Para que a demanda do usuário de CAA seja plena e adequadamente contemplada, é necessária sua participação no processo de escolha e produção do seu sistema (BLACKSTONE; HUNTBERG (2003). O usuário deve ser o stakeholder, isto é, a (pessoa mais importante no processo de intervenção) e suas demandas devem sobrepujar as dos stakeholders indiretos (segunda parte mais interessada no projeto), que são os cuidadores, familiares e amigos. Trata-se de "ouvir" (ser sensível às demandas do usuário de CAA, primeiramente) para implantarem e manterem os recursos de comunicação alternativa de acordo com seus interesses (PAURA, MANZINE, DELIBERATO, 2009).

No entanto, as variáveis extrínsecas ao sujeito também são muito importantes (família, grupo social) nesse processo de intervenção de quem necessita utilizar a CAA. Nesse sentido, a família participa informando as potencialidades e déficits do indivíduo desprovido de comunicação oral. Por outro lado, os recursos de CAA são utilizados ainda para mediar a 
comunicação entre o indivíduo e sua família. Portanto, a família deve ser capacitada para ensinar seus filhos a utilizarem a tecnologia, subsidiando o trabalho da equipe multidisciplinar.

A base do sistema de CAA é a multidisciplinaridade em que profissionais de diversas áreas (fonoaudiologia, pedagogia, fisioterapia, terapia ocupacional, psicologia) interagem com o propósito de somar esforços a partir de condutas remediativas e suplementares, promovendo a inclusão social e educacional daqueles desprovidos de linguagem oral (ARAÚJO, DELIBERATO, BRACIALLI, 2009).

A qualidade da interação da equipe multidisciplinar com a família é de suma importância para o sucesso do trabalho de implementação de recursos de CAA, na esfera acadêmica, existem vários artigos que evidenciam o trabalho da equipe multidisciplinar no âmbito familiar e escolar com o uso da CAA, obtendo resultados de aumento de habilidades e trocas comunicativas dos sujeitos em foco. Entre esses, podemos citar o artigo Comunicação e formas não-verbais de Rita de Cássia Silveira (SILVEIRA apud NUNES, 2009), Maria da Piedade Resende da Costa Cambruzzie (CAMBRUZZIE apud NUNES, 2009) que analisa a implementação da CAA pela mãe de uma adolescente surdocega. Como também o artigo de Adriana Ponsoni (PONSONI apud NUNES, 2009) e suas colaboradoras que descreve a atuação de uma equipe multidisciplinar no âmbito familiar e escolar de duas crianças com paralisia cerebral.

MENDES (2002), no seu livro Perspectivas para a construção da escola inclusiva no Brasil, destaca com veemência a necessidade do trabalho em equipe de forma colaborativa, entre os professores do ensino regular e do ensino especial e entre professores do ensino regular e equipe multidisciplinar.

As pessoas que necessitam de formas alternativas de comunicação dividem-se em três grupos: linguagem expressiva, linguagem de apoio e linguagem alternativa. No primeiro grupo (linguagem expressiva) estão as pessoas que compreendem bem a linguagem oral, porém possuem severas dificuldades para se expressarem através da oralidade. São indivíduos portadores de paralisia cerebral, não possuem controle do seu aparelho fonoarticulátório e, portanto, sua linguagem oral é pouco inteligível. A única forma de Ihes dar voz é através do sistema alternativo de comunicação. $O$ 
segundo grupo (linguagem de apoio) constitui-se de paralisados cerebrais com disartria moderada e leve, portadores de Síndrome de Down com atrasos no desenvolvimento da fala, portadores de afasia e crianças com atrasos no desenvolvimento da linguagem oral sem etiologia. Nesse grupo, a CAA não substitui a fala, é medida temporária de tratamento ou suplementação. No grupo (linguagem alternativa) estão os indivíduos com autismo, portadores de agnosia auditiva e de deficiência mental severa. Este grupo ou não usa a linguagem oral ou raramente usa (MARTINSEN E VON TETZCHNER, 1996; FERNANDES, 1998).

Sendo uma proposta de mediação multidisciplinar, a CAA contempla aspectos não estritamente cognitivos, como fatores emocionais e motivacionais que podem determinar o estilo de aprendizagem da criança e de seu sucesso acadêmico.

Os autores supracitados não deixam de declarar a importância da boa qualidade da relação interpessoal entre mediador e indivíduo com dificuldade oral ao utilizarem recursos de CAA. A boa interação entre os dois (mediador e mediado) implica fatores emocionais e motivacionais positivos, que suscitam à aprendizagem mais eficiente e prazerosa por parte de quem necessita do recurso. Amenizando sobremaneira aspectos como medo de fracassar, medo de errar, atitude defensiva, que por meio do bom relacionamento com o mediador são substituídos por sentimentos de vivacidade, alegria e interesse em aprender e relacionar-se com quem faz a interface utilizando recursos de CAA.

Desta forma, é explícita a responsabilidade dos membros da equipe multidisciplinar que atuam com bastante proximidade dos deficientes que necessitam da CAA. Cabe a estes uma boa formação acadêmica que os habilitem com excelência para executarem suas funções com eficiência e competência. 


\section{A INCLUSÃO ESCOLAR/ DEFICIÊNCIA INTELECTUAL/ NECESSIDADES EDUCACIONAIS ESPECIAIS.}

Principalmente após a Declaração de Salamanca ${ }^{2}$, o tema inclusão escolar vem sendo muito discutido na esfera acadêmica, momento em que essa política educacional começou a ser adotada por vários países, incluindo o Brasil. Nesse documento estão concentradas linhas de ação que geram uma grande discussão sobre a concepção tradicional de escola. A reprodução do modelo escolar tradicional tem impossibilitado as instituições educacionais atenderem aos desafios da inclusão escolar. Visto que, o objetivo precípuo deste novo modelo educacional inclusivo é a educação para todos os alunos, independente de etnia, gênero, condições físicas, sociais, emocionais, intelectuais, etc.

É nessa perspectiva que a educação inclusiva traz em seu bojo um novo paradigma educacional. - Uma escola que necessita modificar-se para atender a diversidade, mediante suas necessidades educacionais especiais. Desta forma, não é o aluno que tem de adaptar-se a escola, porém é a escola que necessita modificar-se para atender a ele.

Dentre as modificações necessárias à escola para o atendimento a todos os alunos destaca-se: Adequação das metodologias de ensino às diferentes necessidades educacionais, adequação de currículos as diversidades socioeconômicas e culturais da região em que a escola está localizada, formação de professores para o ensino inclusivo, dentre outros aspectos. Nesse contexto, a educação inclusiva se contrapõe as práticas escolares tradicionais que limitam a escolarização e a atuação no contexto sócio-cultural de um grupo considerável de pessoas. Portanto, o aluno é visto como um indivíduo que possui condições de definir sua trajetória, de acordo com as bases históricas e culturais instituídas pela própria humanidade. Glat e Pletsch (2012).

Sadao Omote (2008) também evidencia a necessidade de mudanças nas práticas pedagógicas da escola tradicional para que sejam aplicados os princípios da inclusão. Ressaltando o esforço que a escola regular deve envidar para rever velhas crenças e dogmas, gerando possibilidades de 
atendimento às heterogeneidades de alunos com diferentes características e necessidades educacionais especiais.

Mantoan (2006) destaca que existem escolas regulares que já estão cumprindo a Constituição e a LDB transformando e revendo suas metodologias tradicionais antes utilizadas e seus métodos excludentes dando lugar a metodologias e práticas que atendam essa nova proposta escolar de educação para todos. No entanto, a autora ressalta que esse processo de mudança é bastante lento. Entretanto, não pretende provocar mais marginalização do que a escola especial, possuidora de ambientes que segregam e discriminam principalmente alunos que se diferenciam pelas deficiências, destacando a intelectual.

Embora os dados quantitativos nacionais atualizados sejam de difícil acesso, após várias leituras é possível perceber que a deficiência intelectual representa, no âmbito escolar, um dos maiores grupos de deficientes atendidos na rede de ensino público regular. No Ceará, de acordo com dados da SEDUC (Secretaria de Educação do Ceará) em 2015, são 2.818 alunos matriculados na rede pública, desse total $52 \%$ são deficientes intelectuais, 25\% estudantes com surdez e $17 \%$ com baixa visão. Os 6\% restantes estão distribuídos com matrículas de estudantes que possuem outras deficiências. Neste estado, mais da metade dos matriculados na rede pública estadual são deficientes intelectuais

Sabemos que a legislação é explícita quanto à matrícula e ao acolhimento do aluno com necessidades educacionais especiais. Não obstante, o mais importante é que esse aluno tenha condições de desenvolver suas potencialidades e the seja dado condições efetivas de aprendizagem. Nesse sentido, inclusão escolar deve ser definida como um processo muito mais complexo do que apenas o acesso do deficiente e demais alunos com necessidades educacionais especiais à escola.

Nesta perspectiva, cabe destacar que apesar da instituição escolar sempre ter sido um espaço sociocultural onde as diferenças convivem entre si, está sempre teve a homogeneidade como um traço marcante. Desta forma, através de suas políticas e práticas educacionais sempre reproduziu a ordem social, limitando a escolarização somente para alguns e praticando sobremaneira a exclusão. Com o advento da inclusão escolar, essa se depara 
com o desafio de construir um novo conceito de ensino/aprendizagem, que elimine o segregacionismo e ofereça a todos sem distinção, o direito de aprender de acordo com suas especificidades, aspectos estes imbuídos no conceito de diversidade e de escola para todos. Haja vista, que o conceito de necessidades educacionais especiais, contido na inclusão escolar, está vinculado ás dificuldades de aprendizagem, não necessariamente à deficiência. Destacando, portanto, o papel fundamental da escola diante da aprendizagem de cada aluno, de acordo com a necessidade específica individual, quer seja este aluno deficiente ou não, transformando conteúdos em conhecimentos. Desenvolvendo a autonomia e a independência, fatores importantes principalmente para o aluno com necessidade educacional especial.

No caso do aluno deficiente intelectual, seu processo de ensino/ aprendizagem como o dos demais deficientes, requer um planejamento específico de acordo com suas especificidades. Padilha e Braga (2012) afirmam que as atividades relacionadas ao ensino/aprendizagem do aluno deficiente intelectual devem ser voltadas para estimular as funções psicológicas superiores (atenção, percepção, memória, pensamento, abstração, fala etc.), principais dificuldades desse deficiente. No entanto, a autora afirma que professores muitas vezes propõem atividades relacionadas somente ao concreto, partindo da premissa que deficientes intelectuais não são capazes de abstrair. Desta forma, privando-os de desenvolver habilidades concernentes as funções psicológicas superiores.

De acordo com Vygotsky (1997) a escola deve procurar combater as insuficiências do deficiente intelectual através de atividades que desenvolvam seu pensamento abstrato, libertando-o de atividades somente concretas contidas no método visual-direto. Padilha (2014) também reforça esse pensamento quando defende à organização do trabalho pedagógico para deficientes intelectuais que promovam 0 desenvolvimento das funções psicológicas superiores.

Vygotsky (2000) compreende a deficiência em duas dimensões: a primária que defende como sendo de origem biológica e a secundária que se compreende na relação com o tempo, a história e a cultura. De acordo com essa compreensão pode-se afirmar que é na deficiência secundária que se encontra a possibilidade de compensar as limitações impostas pela orgânica 
(biológica). Através da mediação social o conhecimento estabelecido historicamente e culturalmente é construído.

Nesta perspectiva, Oliveira (2013) declara que:

A deficiência está submetida à história e não ao biológico, portanto não é sempre a mesma em todo tempo e lugar, é fluída, mutável, dinâmica, assim depende das relações entre as pessoas e do conhecimento historicamente construído e disponível (OLIVEIRA, 2013, p.90).

Acrescenta ainda, que esse aspecto "muda substancialmente o papel da escola, do currículo, do conhecimento, do professor". Embora não seja tarefa fácil, portanto, para que essa ação aconteça é necessária a mobilização de todos os componentes escolares: sistema escolar, gestão escolar, educação especial, família, etc. Destaca sobremaneira, o papel do professor como "protagonista da sala de aula", [...] "ator principal na relação pedagógica”. (P.93). A autora enfatiza a relação próxima e constante com o aluno na sala de aula gerando a oportunidade real do professor de exercer um papel importante na vida de cada um desses estudantes. É o professor que vai auxiliá-los na construção de seus conhecimentos e autonomias tão necessárias para sua inserção social.

Nesse contexto, no próximo tópico será abordada a contribuição da Teoria Histórico-Cultural para a CAA (Comunicação Alternativa e Ampliada) e/ou suplementar (CSA). No sentido de possibilitar a comunicação e aprendizagem escolar de deficientes com necessidades educacionais especiais. Portanto, inclusão escolar, inclusão social e melhor qualidade de vida para esses deficientes.

\section{O SOCIOINTERACIONISMO DA TEORIA HISTÓRICA CUTURAL (THC) DE VYGOTSKY E A CAA (COMUNICAÇÃO ALTERNATIVA E AMPLIADA)}

Pesquisadores na área da CAA (Comunicação Alternativa e Ampliada) em busca de embasamentos teóricos que facilitem a compreensão da aquisição da linguagem destes usuários reconhecem a grande contribuição de Vygotsky (1984). A THC (Teoria Histórica Cultural) defendida por Vygotsky e 
seus colaboradores, baseia-se na lei geral do desenvolvimento cultural em dois níveis: primeiramente, interpessoal e depois intrapessoal.

Vygotsky contestou as ideias organicistas, vigentes em sua época, que reduziam a deficiência a aspectos puramente biológicos. Sua concepção sobre a deficiência pode ser considerada extremamente moderna para a Rússia do início do século $X X$ ao propor uma abordagem centrada na superação do déficit orgânico.

Atualmente, reconhece-se como a deficiência secundária, em que o indivíduo possui uma incapacidade (disability) e uma desvantagem (handicap) que impedem seu convívio de forma normal na sociedade, visto que esse indivíduo está atrelado ao conjunto de significações sociais (preconceitos, estigmas, estereótipos) que o tornam diferente e perpetuam essa condição recheada de estigmas, sob a visão de uma sociedade composta de pessoas consideradas normais (OMOTE, 2004).

Todavia, o desenvolvimento da CAA e de outras práxis da Psicologia, como a avaliação assistida, têm buscado dirimir as barreiras da exclusão social por meio de alternativas que melhorem a qualidade de vida do indivíduo deficiente, gerando possibilidade de comunicação e, portanto, facilitando seu processo de inserção na cultura. No entanto, o pensador russo é claro em afirmar que, somente através das relações sociais carregadas de significações, surge o desenvolvimento das funções psicológicas superiores ou culturais mediadas pelo outro, por meio da linguagem, signo por excelência.

Vygotsky (2003) se apoia na sua teoria sociohistórica, diretamente relacionada com a qualidade das interações sociais dos grupos aos quais estão inseridos, relacionando o desenvolvimento infantil e humano à sociogênese, ou seja, o desenvolvimento das estruturas do pensamento e da linguagem humana está associado à qualidade das interações sociais dos grupos nos quais estão inseridos. Isto é, a essência do desenvolvimento cultural consiste na apropriação e no domínio do social. Para Vygotsky (2003), a linguagem e outras funções mentais são construídas nas interações sociais da criança, no plano interpsicológico (espaço coletivo de sua mente e seus interlocutores mais experientes).

Durante este processo, que ocorre em espaço compartilhado, surge a fala egocêntrica (acompanha à função motora, auxiliando a criança a resolver 
problemas). Esta fala representa, então, a passagem das funções interpsicológicas para as funções intrapsicólogicas. Assim, concebe-se a junção de dois processos que vinham ocorrendo paralelamente: o pensamento e a fala, passando, então, o pensamento a ser racional e a fala verbal (NUNES, 2003).

O mestre russo preconiza ser a aprendizagem que viabiliza 0 desenvolvimento mental e não o contrário, como afirma Piaget. A fim de esclarecer estas relações, Vygotsky (2003) propôs o conceito de (ZDP) Zona de Desenvolvimento Proximal (onde há sempre dois níveis de desenvolvimento - o real e o proximal). O real é o desenvolvimento que logo se estabeleceu, e passou a existir por meio dos ciclos de desenvolvimentos já completados. No proximal, a criança vai conseguir através das relações interpessoais com seus companheiros mais experientes e mais capazes.

No entanto, esse conceito não se restringe somente às interações professor-aluno, porém a todo contexto sócio-histórico-cultural. As implicações educacionais desta perspectiva são claras, principalmente, para os portadores de necessidades especiais. Segundo Vygotsky (2003), os momentos mais importantes, em geral ou e em particular, de uma criança deficiente ocorrem na zona de desenvolvimento proximal (onde a criança interage com o adulto e absorve elementos culturais, signos símbolos, destacando-se a linguagem. Estes elementos culturais devem ser adaptados às características psicofisiológicas da criança (RIEBER e CARTON,1993).

Contudo, é necessário estabelecer o ponto de convergência entre o desenvolvimento existente (individual) e 0 desenvolvimento cultural (interpessoal), onde se constitui a aprendizagem.

Neste sentido, os sistemas de CAA e todo o arcabouço de estratégias utilizadas pelo adulto para tornar possível a comunicação do portador de distúrbio da fala, podem ser considerados como elementos culturais adaptados às condições psicossociais do indivíduo. Destaque-se a importância do conhecimento sobre a ZDP para o mediador da CAA, no sentido de obter do indivíduo que utiliza estes sistemas de comunicação, principalmente, o aprendizado por meio da intervenção de outro sujeito mais experiente (mediador, família, amigos não deficientes etc.). 
De acordo com (NUNES, 2003), observações das interações mostram que as mensagens dos usuários de CAA não são resultados do ensino através de modelagem, mas resultado de um processo de negociação entre o indivíduo e o seu interlocutor de construção gradual de significados através de sucessivas tentativas. Assim, comunicação não é um traço intrapessoal, mas uma construção interpessoal (LIGHT, 1989, BEDROSIAN,1997)

Ressalte-se, ainda, que diante dos estudos de Vygotsky (2003), é possível afirmar que o desenvolvimento das crianças com necessidades especiais em situações de isolamento social, configura-se como extremamente problemático, principalmente com relação às estruturas do pensamento e da linguagem. $O$ isolamento social, na ótica Vygotskiana, ultrapassa os limites da visão social ou ética e adentra nas questões psicológicas, quando analisa o frequente isolamento na família, na escola ou na vida social.

Portanto, a importância da convivência em grupos heterogêneos enriquece as relações interpessoais através das trocas ampliadas com pares que não se limitam às crianças iguais. A sociogênese, para Vygotsky, é condição primordial para que a criança se desenvolva de forma plena, ou seja, através da qualidade de suas interações sociais com a família, a escola, a comunidade, etc. Quanto mais intensas e positivas forem essas trocas psicossociais, mais enriquecido e fortalecido será o desenvolvimento infantil (VYGOTSKY, 2003).

Em síntese, de acordo com Lev Vygotsky (1997), qualquer pessoa, deficiente ou não, deve ser beneficiada pela visão prospectiva da teoria histórico-cultural do desenvolvimento humano. Isto é, necessita de metas e objetivos iguais, dirimindo a violência da exclusão social.

Finalizando, a Teoria Histórico-Cultural nos ensina que é na vivência social plena que a deficiência se manifesta e deve ser reestruturada de forma positiva, a fim de oferecer para o deficiente novas e melhores possibilidades em sua vida social.

\section{CONSIDERAÇÕES FINAIS}


A CAA surgiu como método suplementar e/ou alternativo para pessoas que por algum motivo não conseguem se comunicar por meio da linguagem oral. A literatura tem mostrado conjuntos e sistemas de símbolos que possibilitam a comunicação interpessoal dos indivíduos desprovidos da fala. No entanto, o que se constata em algumas pesquisas é que, apesar da necessidade precípua da utilização desses equipamentos, ainda são pouco utilizados em escolas públicas de educação especial que recebem alunos não falantes.

Outro aspecto importante é a multidisciplinaridade que conduz a área da educação especial, gerando várias discussões que envolvem profissionais como fonoaudiólogos, terapeutas ocupacionais, fisioterapeutas, educadores físicos, psicólogos. De tal modo, a multidisciplinaridade precisa tornar-se evidente no cotidiano das escolas, como ensino colaborativo entre professores e consultores de áreas afins, professores do ensino regular e do ensino especial, tornando o trabalho realmente "inter" e "multi" disciplinar, em que as diversas áreas se complementam para atender as peculiaridades do aluno especial.

Assim sendo, estudiosos da CAA, sedentos de conhecimentos para subsidiar a compreensão do processo de aprendizagem de alunos deficientes com dificuldades na fala ou não falantes, estudam a teoria sociointeracionista de Vygotsky - que através da compreensão da Zona de Desenvolvimento Proximal (ZDP) - explica a necessidade da mediação do profissional que trabalha com a CAA e o indivíduo que necessita desses sistemas de comunicação.

Vygotsky (1997) explicita em sua obra a necessidade do conhecimento do ponto de interseção entre o conhecimento que o aluno domina e o conhecimento que vai adquirir através do mediador. Para o estudioso russo, a aprendizagem se inicia exatamente no trabalho mediante esta convergência. Através de relações sociais embasadas na afetividade e nas relações interpessoais entre os indivíduos que necessitam de mediação e seus possíveis mediadores (professores, família e profissionais que trabalham com a CAA).

Enfim, o processo de inclusão escolar de alunos com deficiência em geral, (incluindo os deficientes intelectuais nos quais foca o artigo), com ou sem 
dificuldades na linguagem oral, requer ações de diferentes profissionais, com o objetivo de propor adaptações curriculares necessárias às peculiaridades dos alunos com deficiências.

Nesta ótica, a formação de professores habilitados para trabalharem com o deficiente, propiciando atendimento individualizado e que atenda as suas necessidades específicas e não somente meras adaptações é um ato de urgência. Portanto, a inclusão possui uma enorme e difícil tarefa de oferecer educação de qualidade a todos (deficientes ou não), por vivermos num país de muitas diferenças sociais, raciais, culturais, étnicas e principalmente econômicas (OMOTE, 1994).

\section{REFERÊNCIAS BIBLIOGRÁFICAS}

ARAÚJO, R. C. T.; DELIBERATO, D.; BRACIALLI, L. M. P. A comunicação alternativa como área de conhecimento nos cursos de educação e da saúde. In: DELIBERATO, D.; GONÇALVES, M. J.;MACEDO, E. C. (Org.). Comunicação alternativa: teoria, prática, tecnologias e pesquisa. São Paulo: Memnon Edições Científicas, p.. 275-284. 2009.

BEDROSIAN, J. Language acquisition in young AAC systems users: Issues and directions for future research. Augmentative and Alternative Communication, 13, pp. 179-185. 1997.

BLACKSTONE, S.; HUNT BERG, M. Social Networks: a communication inventory for individuals whith complex communication needs and their communication partners. Monterey: Augmentative Communication Inc., 2003.

BLOOM, L; LAHEY, M. Language development and language disorders. New York: John Wiley \& Sons, 1978.

FERNANDES, A. A utilização precoce de comunicação suplementar e/ou alternativa. In: F. C. Capovilla;M.J. Gonçalves\& E. Coutinho (Orgs.), Tecnologia em (RE) Habilitação Cognitiva: uma perspectiva multidisciplinar. São Paulo: EDUNISC. p.227-230. 1998.

LIGHT, J. Reflections on the contexts of language learning for children who use aided AAC., Augmentative and Alternative Communication, pp.158171. 1989.

MANTOAN, M. T. E. Igualdade e diferenças na escola: como andar no fio da navalha In: Inclusão escolar: Pontos e Contapontos. MANTOAN, M. T. E. PRIETO R. G.; ARANTES, V. A. (org.) - 5 ed. São Paulo: Summus, 2006.

MARTINSEN, H.\& Von TETZCHNER, S. Situating augmentative and alternative communication intervention. In $S$. von Tertzchner e $M$, H.Jensen(Eds) 
Augmentative and alternative communication: European perspectives $\mathrm{pp}$. 37-48. London: San Diego. 1996.

MENDES, E. G. Perspectivas para a construção da escola inclusiva no Brasil. In: PALHARES, M. S. MARINE, S. Escola Inclusiva. São Carlos: Ed. UFSCar, 2002.

NUNES, D. R. DE P. Linguagem e Comunicação Alternativa. Apresentação. In: MANZINE, E. J. MARQUEZINE, C. M. TANAKA, E. D. O. FUJISAWA, D.S. BUSTO. R. M. (Org.). Linguagem e Comunicação Alternativa: Londrina: ABPEE, 2009.

NUNES, L. R. O. P. (Org.) Modelos Teóricos da Comunicação Alternativa e Ampliada In: Favorecendo o desenvolvimento da comunicação em crianças e jovens com necessidades especiais. Rio de Janeiro: Dunya, 2008.

Construção de sentenças com uso de sistema pictoalternativa: Contribuição para estudos sobre memória e desenvolvimento da sintaxe. In: MENDES, E. G.; ALMEIDA, M. A.; HAYASHI, M. C. P. I. (Org.). Temas em Educação Especial: conhecimentos para fundamentar a prática. Araraquara: Junqueira \& Marin, p. 145-159. 2008

D. R. P. Introdução. In: MANZINI, E. J. et al. Linguagem e Comunicação Alternativa. Londrina: ABPEE, 2009. P. OLIVEIRA, A. A. S. Deficiência Intelectual e Saber Escolar: A Questão da Avaliação da Aprendizagem. In: MANZINE, J. M. (Org). Educação Especial e Inclusão Temas Atuais. Marquezine \& Manzine Editora. São Carlos. ABPEE, p. 90-93. 2013

OMOTE,S. ( Org.) Inclusão: Intenção e realidade. Marília; Fundepe, 2004.

Diversidade Educação e Sociedade Inclusiva. In: OLIVEIRA, A. A. S.; OMOTE, S. GIROTO, C. R. M. (Org.). Inclusão escolar: as contribuições da educação especial. São Paulo: Cultura Acadêmica, 2008.

OLIVEIRA A. A. S. Deficiência e Saber Escolar: A Questão da Avaliação da Aprendizagem. In: Educação Especial e inclusão - Temas Atuais. MANZINE. J. E. (Org.) São Carlos; Marquezine e Manzine; ABPEE, 2013

PADILHA, A. M. L.: BRAGA, E. F. P. Escola Básica: condições concretas de existência. In: Cadernos de Pesquisa em Educação, Vitória, v.18, n.35, p.113-130, 2012.

. Desenvolvimento Cultural e Educação Especial: Aporte Teórico para PENSAR o Desenvolvimento Psíquico do Deficiente Intelectual (89-114).p.96 In: Ciência e Conhecimento em Educação Especial. OMOTE Sadao, OLIVEIRA Anna Augusta Sampaio de, CHACON Miguel Cláudio Moriel (Orgs.) São Carlos; Marquezine e Manzine; ABPEE, 2014. 
PLETSCH, M. D. e GLAT, R. A escolarização de alunos com deficiência intelectual: Uma aplicação do plano de desenvolvimento educacional individualizado. Linhas Criticas, v.18 n.35, p. 193-208, $2012 .$.

PAURA, A. C.; MANZINE, E. J. DELIBERATO, D. Percepção de Usuários de Comunicação Alternativa e Ampliada e/ou Suplementar em Relação ao Recurso de Comunicação. In: MANZINE, E. J. MARQUEZINE, C. M. TANAKA, E. D.O. FUJISAWA, D. S. BUSTO. R. M. M.(Org.). Linguagem e Comunicação Alternativa. Londrina: ABPEE, 2009.

REILY, L. Linguagem e Comunicação Alternativa. Londrina: ABPEE, 2009.

RIEBER, R. \& CARTON, A. The collected works of L.S. Vygotsky. Volume2: The fundamentals of defectology. NewYork: Plenum. 1993.

VYGOSTKY, L. S. A construção do pensamento e da linguagem. São Paulo: Martins Fontes, 2000.

A Formação Social da Mente. (J Cipolla Neto, L. S. M. Barreto \& S C. Afeche, Trads.). São Paulo: Martins Fontes. 1984.

A formação social da mente. São Paulo: Martins Fontes,

2003.

Escogidas, v. 5). 1997.

Fundamentos da defectologia. Madrid: Visor, (Obras

VON TETZCHNER, S. Suporte ao desenvolvimento da comunicação suplementar e alternativa. In: DELIBERATO, D.; GONÇALVES, M. J.; MACEDO, E. C. (Org.). Comunicação alternativa: teoria, práticas, tecnologias e pesquisa. São Paulo: Memnon Edições Científicas, p. 14-27.2009

Augmentative and alternative communication: assessment and intervention - a functional approach. Theoretical aspects. Department of Psychology, University of Oslo, Norway. Manuscrito não publicado, 1997.

'Doutoranda da UNESP - (Universidade estadual Paulista "Julio de Mesquita Filho". Professora do IFCE - (Instituto Federal de Educação Ciência e Tecnologia do Ceará.) Pedagoga. Especialista em Planejamento Educacional e Psicopedagogia. Mestra em Gestão Negócios Turísticos.

${ }^{2}$ Produto da Conferência Mundial sobre Necessidades Educacionais Especiais Acesso e Acessibilidade, promovida pela Unesco e pelo governo da Espanha, em 1994, da qual participaram cerca de cem países e inúmeras organizações internacionais. A Declaração de Salamanca propôs princípios já consagrados em outras conferências internacionais sobre o tema, como a Conferência Mundial de Educação para Todos, realizada em 1990 em Jomtien, na Tailândia, e a Conferência de Nova Délia, na Índia, em 1993. 
RECEBIDO EM: Maio de 2015 APROVADO EM: Julho de 2015 